\title{
Synthesis and characterization of magnetic-molecularly imprinted polymers for the HPLC-UV analysis of ametryn
}

\author{
Sabir Khan ${ }^{\mathrm{a}, \mathrm{b}}$, Sajjad Hussain ${ }^{\mathrm{c}}$, Ademar Wong ${ }^{\mathrm{a}, \mathrm{b}}$, Marcos Vinicius Foguel ${ }^{\mathrm{a}, \mathrm{b}}$, \\ Luís Moreira Gonçalves ${ }^{\mathrm{d}}$, Maria Isabel Pividori Gurgo ${ }^{\mathrm{e}}$, Maria del Pilar Taboada Sotomayor ${ }^{\mathrm{a}, \mathrm{b}, *}$ \\ a Instituto de Química, UNESP-Univ Estadual Paulista, Departamento de Química Analítica, Araraquara, SP, Brazi \\ ${ }^{\mathrm{b}}$ National Institute for Alternative Technologies of Detection, Toxicological Evaluation and Removal of Micropollutants and Radioactives (INCT-DATREM), Araraquara, \\ SP, Brazil \\ ${ }^{c}$ Faculty of Materials and Chemical Engineering, GIK Institute of Engineering Sciences and Technology, Topi, Pakistan \\ ${ }^{\mathrm{d}}$ REQUIMTE/LAQV, Departamento de Química e Bioquímica, Faculdade de Ciências, Universidade do Porto (FCUP), Porto, Portugal \\ e Department of Analytical Chemistry, Universitat Autònoma de Barcelona, Spain
}

\section{A R T I C L E I N F O}

\section{Keywords:}

Analytical chemistry

Environmental analysis

Food analysis

Food quality

Pesticide

\begin{abstract}
A B S T R A C T
Magnetic molecularly imprinted polymer (mag-MIP) were developed for the analysis of ametryn (4-N-ethyl-6methylsulfanyl-2- $N$-propan-2-yl-1,3,5-triazine-2,4-diamine), a popular triazine herbicide. Iron oxide $\left(\mathrm{Fe}_{3} \mathrm{O}_{4}\right)$ nanoparticles were synthetized, and then modified with tetraethoxysilane (TEOS) and 3-mercaptopropyltrimethoxysilane (MPS). Then MIPs' polymerimerization occurred in the nanoparticles' surface, using ethyleneglycol-dimethacrylate (EGDMA) as the building monomer, 2,2'-azobis(2-methylpropionitrile) (AIBN) as the radical initiator, and 2-vinylpyridine as the functional monomer. The functional monomer was previously chosen by computational simulation. The mag-MIPs' adsorption behavior well-fitted a Langmuir model $\left(\mathrm{q}_{\mathrm{m}}\right.$ of $8.6 \mathrm{mg} \mathrm{g}^{-1}, \mathrm{~K}_{\mathrm{L}}$ of $\left.5.2 \mathrm{~L} \mathrm{mg}^{-1}\right)$ and pseudo first order kinetics $\left(\mathrm{k}_{1}\right.$ of $\left.2.5 \times 10^{-4} \mathrm{~s}^{-1}\right)$. The developed analytical methodology, using high-performance liquid chromatography with UV detection (HPLC-UV), showed suitable selectivity and had a limit of detection (LOD) and quantification (LOQ) of 25 and $82 \mathrm{nmol} \mathrm{L}^{-1}$, respectively.
\end{abstract}

\section{Introduction}

Ametryn is a herbicide in the relevant group of triazines [1], it is particularly used to control weeds in various crops like sugar cane or corn, among others $[2,3]$. Its water solubility is about $185 \mathrm{mg} \mathrm{L}^{-1}, \mathrm{Log}$ $\mathrm{K}_{\mathrm{ow}}$ of $3, \log \mathrm{K}_{\mathrm{oc}}$ of 2.5 , and its contamination levels range up to 0.13 and $0.35 \mu \mathrm{g} \mathrm{L}^{-1}$ in surface water and ground water respectively $[1,4]$. In general, legislation considers levels above $0.5 \mu \mathrm{g} \mathrm{L}^{-1}$ in water intended to human consumption to be unsafe [1]. Even though the use of pesticides has many decades, the development of analytical methods for their determination still remains a hot topic in analytical chemistry [5-7].

Since ametryn is so widely used, it is of huge relevance its swift determination in environmental samples, but of course, also in food samples. Some analytical methods can be found in literature making use of a wide range of techniques like liquid chromatography with mass spectrometric detection (LC-MS) $[3,8]$, gas chromatography with mass spectrometric detection (GC-MS) $[9,10]$, anodic stripping voltammetry [11], surface-enhanced Raman spectroscopy [12], surface plasmon resonance (SPR) [13], ion mobility spectrometry [14] or micellar electrokinetic capillary chromatography [15]. However these methods are usually associated with sample preparation techniques, crucial to remove matrix effects and even to obtain enriched extracts of trace analytes [16]. Some of the sample preparation techniques that have been applied include microwave-assisted solvent extraction [11], solidphase microextraction (SPME) [9,10,14], liquid-liquid extraction [17] or solid-phase extraction [8].

Molecularly imprinted polymers (MIPs) are an interesting sample preparation tool in environmental research for the separation and analysis of organic contaminants from wastewater due to their minute size, greater surface area and selectivity towards the target molecules [10,13,18-23]. MIPs recently evolved to magnetic MIPs (mag-MIPs), these particles improve the separation and opened a new window for analyzing compounds in complex sample matrices [24]. Among other advantages, these hybrid materials offer enhanced selectivity, durability, and the possibility of reuse [25-29]. Recent reviews detail the wige range of possibilities using these interesting materials [30-32]. In this work, mag-MIPs for ametryn were developed and characterized aiming its application within an analytical methodology.

\footnotetext{
* Corresponding author at: Instituto de Química, UNESP-Univ Estadual Paulista, Departamento de Química Analítica, Araraquara, SP, Brazil

E-mail addresses: luis.goncalves@fc.up.pt (L. Moreira Gonçalves), mpilar@iq.unesp.br (M.d.P. Taboada Sotomayor).
} 


\section{Materials and methods}

\subsection{Chemicals and samples}

All chemicals were of analytical grade and were used as received without further purification. Ultrapure water (resistivity not lower than $18.2 \mathrm{M} \Omega \mathrm{cm}$ at $298 \mathrm{~K}$ ) from a Direct-Q 3UV water purification system (Millipore) was used in all experiments. Ametryn, iron(III) chloride hexahydrate $\left(\mathrm{FeCl}_{3} \cdot 6 \mathrm{H}_{2} \mathrm{O}\right)$, iron(II) chloride tetrahydrate $\left(\mathrm{FeCl}_{2} \cdot 4 \mathrm{H}_{2} \mathrm{O}\right)$, 2-vinylpyridine, 3-mercaptopropyltrimethoxysilane (MPS), ethyleneglycol-dimethacrylate (EGDMA) and 2,2'-azobis(2-methylpropionitrile) (AIBN), atrazine, ciprofloxacin and folic acid were purchased from Sigma-Aldrich. Ammonium hydroxide, sodium hydroxide and hydrochloric acid were purchased from Synth-Brazil. Tetraethoxysilane (TEOS) was obtained from Acros Organics.

Food samples were purchased in local supermarkets.

\subsection{Molecular modeling}

Computer simulation was used to calculate the association-free energies interaction, in vacuo, between ametryn and several functional monomers commonly employed for MIP synthesis. The molecular mechanics studies were performed using the softwares HyperChem v. 8.0.5, OpenEye software package and VIDA v. 3.0.0 and the multiple minimum hypersurfaces with MOPAC program. Further details can be found in literature [33].

\subsection{Mag-MIPs' synthesis}

The synthesis of the Mag-MIPs is schematized in Fig. 1. The nanoparticles were prepared by dissolving $\mathrm{FeCl}_{3} \cdot 6 \mathrm{H}_{2} \mathrm{O}$ (4.72 $\mathrm{g}$ ) and $\mathrm{FeCl}_{2} \cdot 4 \mathrm{H}_{2} \mathrm{O}(1.72 \mathrm{~g})$ in $80 \mathrm{~mL}$ of water with vigorously stirring under nitrogen environment. Ammonium hydroxide $(10 \mathrm{~mL}, 28 \%$ in water) was added to the system drop by drop and the reaction was kept at
$80{ }^{\circ} \mathrm{C}$ for about $30 \mathrm{~min}$. The black precipitate (the nanoparticles of $\mathrm{Fe}_{3} \mathrm{O}_{4}$ ) was removed using a magnet, then some unreacted chemicals were washed away using water and dried under vacuum. The particles of $\mathrm{Fe}_{3} \mathrm{O}_{4}$ were further modified by dispersing $300 \mathrm{mg}$ in $40 \mathrm{~mL}$ of ethanol and $4 \mathrm{~mL}$ of water by ultra-sonication for $15 \mathrm{~min}$. Then $5 \mathrm{~mL}$ of ammonium hydroxide and $2 \mathrm{~mL}$ of TEOS were added to the mixture and left to completely react for $12 \mathrm{~h}$ at $25^{\circ} \mathrm{C}$. The materials were then separated using a magnet, and were washed with water and dried in vacuum (completing step I of Fig. 1).

These $\mathrm{Fe}_{3} \mathrm{O}_{4} @ \mathrm{SiO}_{2}$ particles were subsequently altered with MPS. The $250 \mathrm{mg}$ of the $\mathrm{Fe}_{3} \mathrm{O}_{4} @ \mathrm{SiO}_{2}$ were added to $50 \mathrm{~mL}$ of toluene (anhydrous) containing $5 \mathrm{~mL}$ of MPS and the mixture was left under dry nitrogen atmosphere for $12 \mathrm{~h}$ (completing step II of Fig. 1).

Meanwhile, an association of ametryn $(0.2 \mathrm{mmol})$ with the functional monomer 2-vinylpyridine $(0.8 \mathrm{mmol})$ was added into ethanol $(30 \mathrm{~mL})$ with agitation in a water bath at $25^{\circ} \mathrm{C}$ for about $12 \mathrm{~h} .200 \mathrm{mg}$ of the produced $\mathrm{Fe}_{3} \mathrm{O}_{4} @ \mathrm{SiO}_{2}$-MPS were added into this system and subject to agitation for about $3 \mathrm{~h}$. Then, $0.05 \mathrm{mmol}$ of AIBN (the radical initiator) and 4.0 mmol of EGDMA (the building monomer, also known as cross-linking mediator) were added and sonicated in a water bath for $5 \mathrm{~min}$. The mixture was purged using nitrogen gas during $5 \mathrm{~min}$ and the mixture was left to react at $60^{\circ} \mathrm{C}$ in a nitrogen atmosphere for $24 \mathrm{~h}$ (completing step III of Fig. 1).

Subsequently the material was washed out by Soxhlet using acetic acid and methanol $(1: 9, v / v)$ during $48 \mathrm{~h}$, changing the eluent every $8 \mathrm{~h}$ (step $\alpha$ in Fig. 1). The used eluent was analyzed by HPLC-UV and, when no analyte was detected, that meant that a thoroughly wash of the template was achieved. The obtained material was dried at $40{ }^{\circ} \mathrm{C}$ under vacuum, by this way completing the mag-MIPs synthesis. The magnetic non-imprinted polymers (mag-NIPs) were fabricated in a similar manner under the same conditions however without any analyte $[34,35]$.

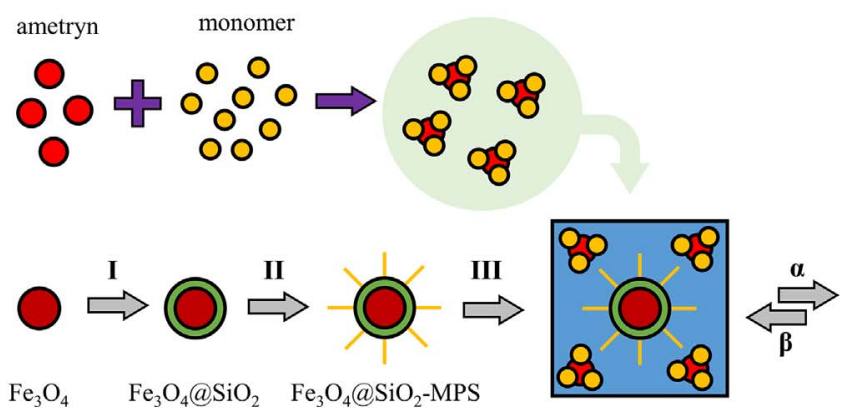

A

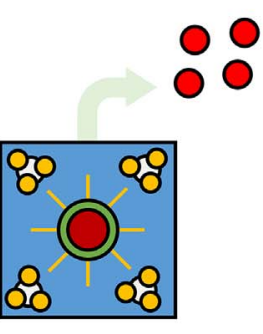

Fig. 1. A) Schematic representation of the mag-MIPs' synthesis. I - Modification of the $\mathrm{Fe}_{3} \mathrm{O}_{4}$ with TEOS, ca. $12 \mathrm{~h}$ in $\mathrm{NH}_{4} \mathrm{OH}$, forming $\mathrm{Fe}_{3} \mathrm{O}_{4} @ \mathrm{SiO}_{2}$; II - Modification of the $\mathrm{Fe}_{3} \mathrm{O}_{4} @ \mathrm{SiO}_{2}$ with MPS, for about $12 \mathrm{~h}$ in toluene, forming $\mathrm{Fe}_{3} \mathrm{O}_{4} @ \mathrm{SiO}_{2}$-MPS; III - Reaction between the $\mathrm{Fe}_{3} \mathrm{O}_{4} @ \mathrm{SiO}_{2}$ MPS particles and the product of the supramolecular reaction of the analyte (ametryn) and the functional monomer (2-vinylpyridine) in an environment with AIBN and EGDMA, for about $24 \mathrm{~h}$ at $60{ }^{\circ} \mathrm{C} ; \alpha$ - eluting, i.e. losing the analyte creating the imprinted spots; $\beta$ - rebinding, the oppose process of eluting, filling the imprinted holes with the analyte. B) Schematic representation of the experimental procedure.

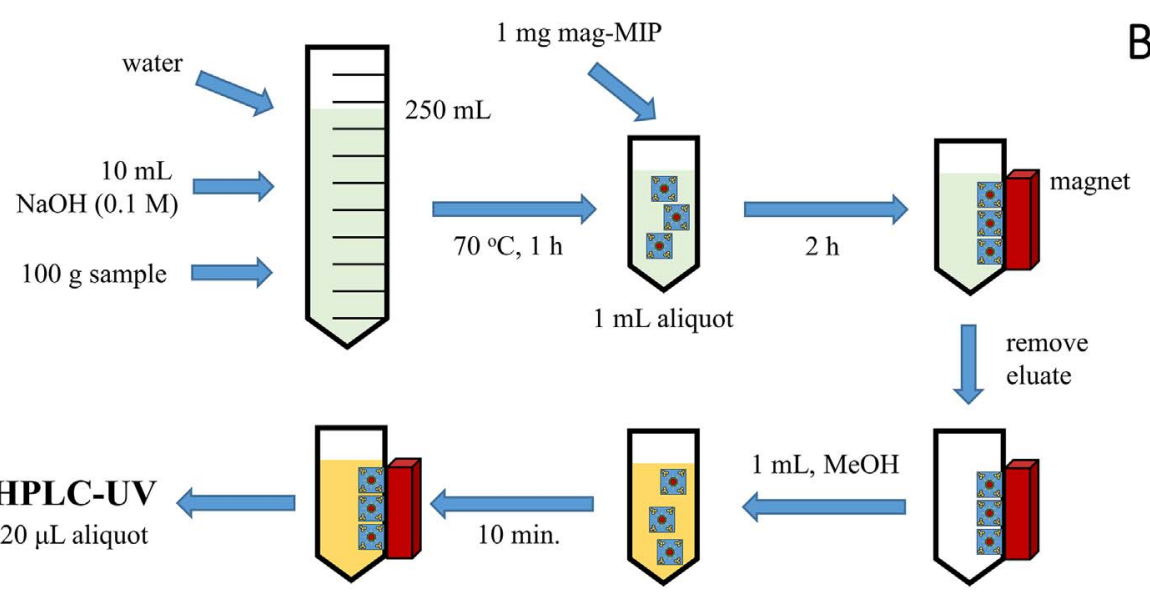


Table 1

List of monomers used in the simulation along with the results obtained in the semiempirical computational simulation.

\begin{tabular}{ll}
\hline Monomers & Binding energy/kJ mol ${ }^{-1}$ \\
\hline 2-Vinylpyridine & $-115 \pm 1$ \\
1,3-Divinylbenzene & $-108 \pm 1$ \\
4-Imidazoleacrylic acid & $-107.4 \pm 0.6$ \\
Allylamine & $-90 \pm 1$ \\
1-Vinylimidazole & $-88.9 \pm 0.8$ \\
2-(Diethylamino)ethyl methacrylate & $-71.7 \pm 0.1$ \\
Methacrylic acid & $-71.0 \pm 0.6$ \\
Acrylamide & $-68 \pm 4$ \\
2-Hydroxyethyl methacrylate & $-67.6 \pm 0.7$ \\
Styrene & $-66.4 \pm 0.8$ \\
2-Acrylamido-2-methyl-1-propanesulfonic acid & $-61 \pm 1$ \\
Acrylonitrile & $-54.7 \pm 0.3$ \\
$N, N$-methylenebisacrylamide & $-47 \pm 2$ \\
4-Imidazoleacrylic ethyl ester & $-42 \pm 1$ \\
Acrylic acid & $-42 \pm 2$ \\
Acrolein & $-31 \pm 1$ \\
Methylenesuccinic acid & $-25.6 \pm 0.2$ \\
\hline
\end{tabular}

\subsection{Characterization}

The textural properties were studied by $\mathrm{N}_{2}$ sorption measurements at $77 \mathrm{~K}$ (liquid nitrogen temperature) using a Micromeritics Gemini VII $2390 \mathrm{t}$. Prior to the adsorption experiments, samples were degassed in vacuum with helium at $80^{\circ} \mathrm{C}$ for $4 \mathrm{~h}$. The average pore sizes of the polymers were estimated by the Barrett-Joyner-Halenda (BJH) method. Specific surface areas were calculated according to the Brunauer-Emmett-Teller (BET) method. Scanning electron microscopy (SEM) was performed with a JEOL JSM 6330F equipped with a field emission gun (FEG).

\subsection{High-performance liquid chromatography with UV detection}

The chromatographic analysis were carried out by a high-performance liquid chromatography (HPLC) model Shimadzu 20A coupled with SPD-20A UV detector and a $\mathrm{C}_{18}$ column, $250 \times 4.6 \mathrm{~mm}, 5 \mu \mathrm{m}$ particle size, $100 \AA$ pore size (Kinetex from Phenomenex). The mobile phase was composed of $1 \%$ phosphoric acid and acetonitrile (60:40, v/ v), at a flow rate of $1.0 \mathrm{~mL} \mathrm{~min}^{-1}$, the injection volume was $20 \mu \mathrm{L}$ and the wavelength set was $220 \mathrm{~nm}$. The retention time for ametryn was around $3.9 \mathrm{~min}$. The mobile-phase for ciprofloxacin was composed of phosphoric acid and acetonitrile $(80: 20, \mathrm{v} / \mathrm{v})$ and wavelength of $280 \mathrm{~nm}$, for atrazine the mobile phase was water and acetonitrile $(80: 20, \mathrm{v} / \mathrm{v})$ and wavelength of $220 \mathrm{~nm}$, whereas for folic acid it was water and acetonitrile $(60: 40, \mathrm{v} / \mathrm{v})$ and wavelength of $280 \mathrm{~nm}$ (these three compounds were analyzed in the selectivity studies).

\subsection{Adsorption experiments}

Binding capacity of the prepared mag-MIPs and mag-NIPs adsorption tests were tested by adding $2 \mathrm{mg}$ of the mag-MIPs or the mag-NIPs in a separated vials and adding $2.0 \mathrm{~mL}$ of solutions with different concentrations of the ametryn, using a ametryn standard stock solution ( $20 \mathrm{mg} \mathrm{L}^{-1}$ ) prepared in methanol. The mixture was shaken in a rotating shaker for $120 \mathrm{~min}$, then the magnetic polymer suspensions were separated using a magnetic bar and filtered with a $0.45 \mu \mathrm{m}$ membrane (polyester, diameter of $25 \mathrm{~mm}$, purchased from Chromafil).

\subsection{Sample preparation}

The schematics of the analytical procedure are shown is Fig. $1-\mathrm{B}$. $100 \mathrm{~g}$ of each sample (tomato, capsicum and strawberry) were crushed in a mixer in the presence of $10 \mathrm{~mL}$ of sodium hydroxide, $0.1 \mathrm{~mol} \mathrm{~L}^{-1}$ and water that completed the volume. Then, this mixture was heated at
$70{ }^{\circ} \mathrm{C}$ for about $1 \mathrm{~h}$. Aliquots of $1 \mathrm{~mL}$ were removed to small vials, some of them were spiked using an ametryn standard stock solution ( $20 \mathrm{mg} \mathrm{L}^{-1}$ in methanol), $1 \mathrm{mg}$ of mag-MIPs were added and left to react during $2 \mathrm{~h}$ with agitation. After adsorption, the mag-MIPs were retained inside the vial using a magnet. Then $1 \mathrm{~mL}$ of methanol was added to promote desorption, this was performed with agitation for about $10 \mathrm{~min}$. Aliquots of the obtained extract, after using a magnet to 'decant' the mag-MIPs and filtration, were analyzed by HPLC-UV (this was performed according to what was previously described in section 2.5. HPLC-UV).

\section{Results and discussion}

\subsection{Mag-MIP development and characterization}

Computational studies of molecular mechanics were performed to select the most suitable monomer for the fabrication of the imprinted polymer. The optimized structure and energy of the pre-polymerization of ametryn with normally available monomers was calculated. It was observed that 2-vinylpyridine, 1,3-divinylbenzene and 4-imidazoleacrylic acid presented the highests binding energies with ametryne, in that order, (Table 1). A higher binding energy assumes an expected better interaction with the analyte. Probably, the superior value of binding energy is due to the $\pi-\pi$ interaction between the aromatic ring of template and the aromatic ring of these three functional monomers $[36,37]$. The 2-vinylpyridine may have presented the highest binding energy because this monomer can also interact by hydrogen bonding between the nitrogen of aromatic ring of 4-vynilpiridine and the amines in ametryn's structure [38]. The monomers with intermediary binding energy, such as: allylamine, 2-(diethylamino)ethyl methacrylate, methacrylic acid (MAA), acrylamide, 2-hydroxyethyl methacrylate and 2acrylamido-2-methyl-1-propanesulfonic acid, have in their structure atoms of amine, amide or carboxylic groups. These groups, in general, provide hydrogen bonds with the analyte, then the intermediary energy is probably due to this interaction [13,39-42]. For the mag-MIPs' synthesis, 2-vinylpyridine was chosen due to its higher binding energy and the possibility of two kinds of interaction with analyte. Fig. S1 in the supporting information schematizes the possible interactions.

Koohpaei et al. described the chemometric optimization of a MIP to ametryn (template - T) using methacrylic acid as the functional monomer (FM) and EGDMA as the build monomer (BM) [41]. The authors reported the molar ratio 1:4 between T-FM presents a good stability for complex formation, thereby the molecularly imprinted effect is improved. Furthermore, the T-BM proportion around of 1:20 facilitates the mass transfer of the analyte to rebinding to the cavities of imprinted polymer. According to the results, obtained from experimental design, the optimum molar ratio of T-FM-BM is 1:4.49:22.48. Thus, the mag-MIP in this work was synthetized using the proportion $1: 4: 20$, which is a rounding to the optimum proportion proposed by Koohpaei et al. [41,42], it is also a common proportion in literature [43].

From the SEM images (Fig. 2) it seems that there is a considerable difference in the morphology between the mag-MIPs and the mag-NIPs. The morphological differences could be due to variations that occur in the structure of the MIP during the template removal. The mag-MIPs seem to have created a larger number of micropores $(<2 \mathrm{~nm}$ diammeter) groups and less aggregates of mesopores (2-50 nm diammeter) and macropores (> $50 \mathrm{~nm}$ diammeter) [33]. According to the BET and BJH measurements [33], Mag-MIPs are more porous and granular than the control, which is confirmed by the difference in surface area between the two polymers, mag-MIPs have indeed a greater surface area $\left(50.6 \mathrm{~m}^{2} \mathrm{~g}^{-1}\right)$ than the mag-NIPs $\left(26.7 \mathrm{~m}^{2} \mathrm{~g}^{-1}\right)$, along with greater pore volume per mass for the mag-MIPs $\left(25.5 \mathrm{dm}^{3} \mathrm{~g}^{-1}\right)$ than the magMIPs $\left(13.4 \mathrm{dm}^{3} \mathrm{~g}^{-1}\right)$. XRD and FTIR caractherization can be found in the supporting information (as Fig. S2 and Fig. S3, respectively).

Fig. 3 shows the binding capacity of ametryn on mag-MIPs and mag- 

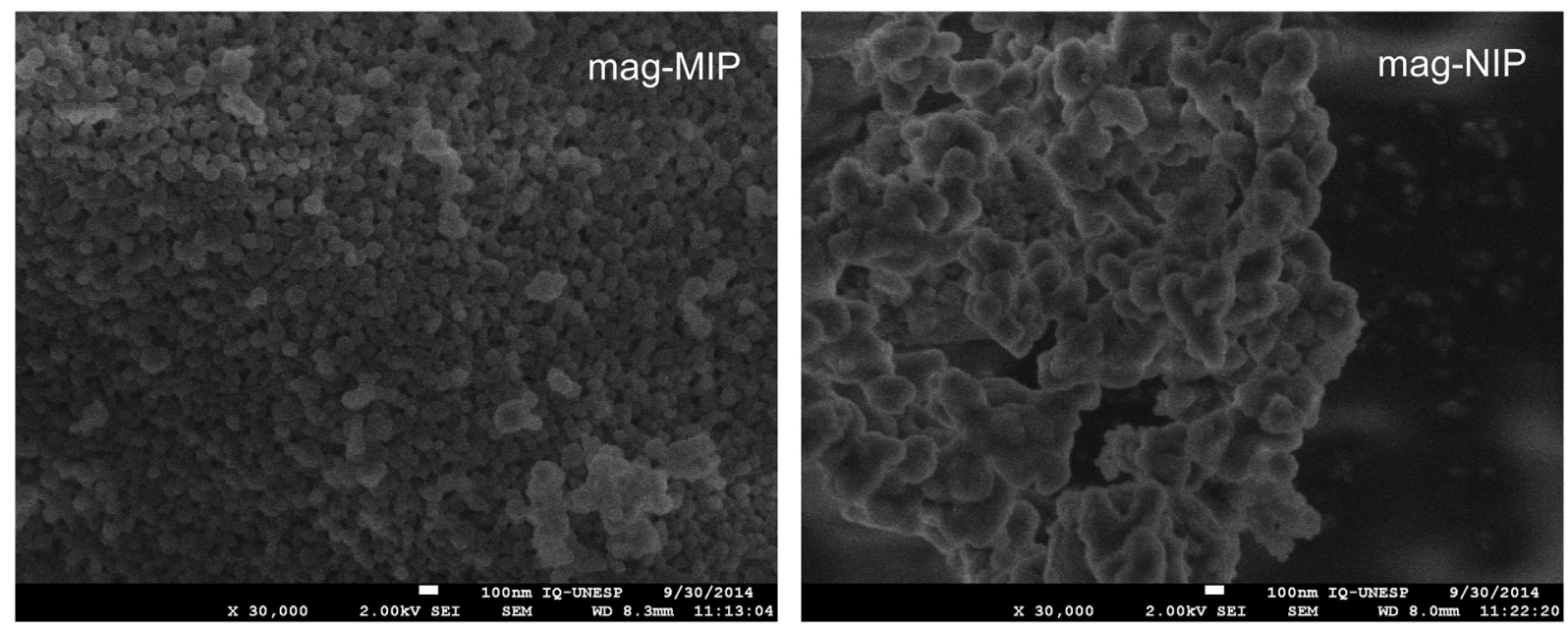

Fig. 2. SEM images of mag-MIPs and mag-NIPs $(30.000 \times$ amplification).

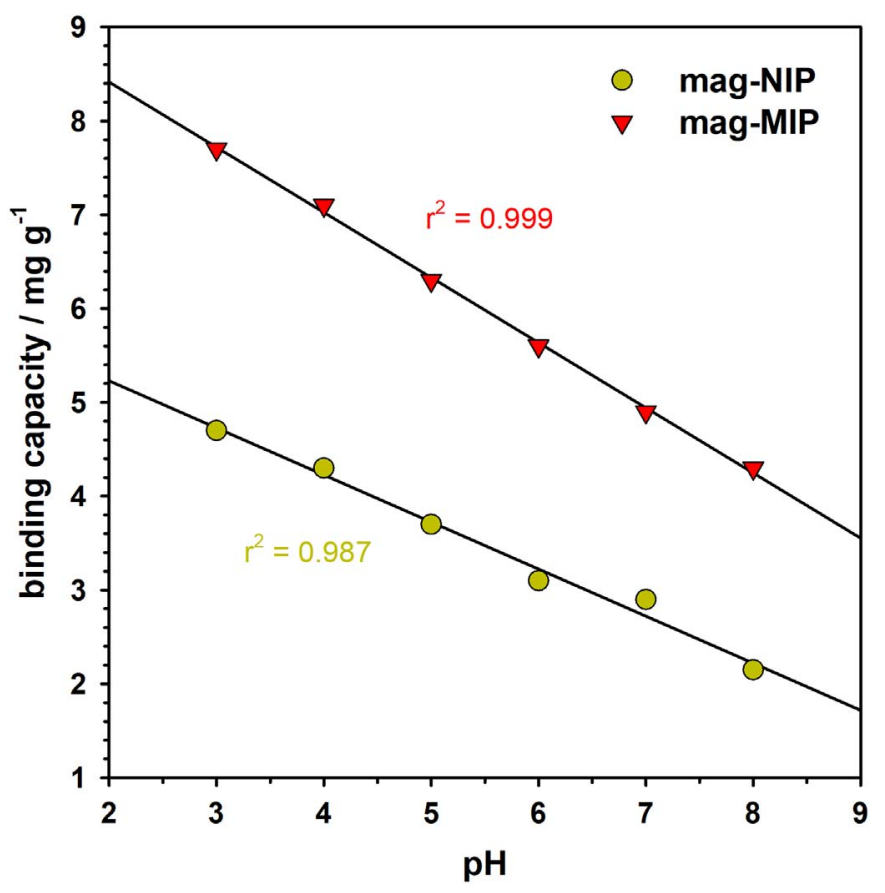

Fig. 3. pH studies for the adsorption of ametryn on mag-MIPs and mag-NIPs.

NIPs at various $\mathrm{pH}$ values. The sorption of ametryn on the mag-MIPs is low in basic $\mathrm{pH}$ and increases linearly in acidic medium up to the tested $\mathrm{pH}$ 3.0. An analogous tendency was observed for the sorption of magNIPs. Since ametryn's $\mathrm{pk}_{\mathrm{a}}$ is around 4.1 [44], with a less acidic $\mathrm{pH}$ ametryn deprotonation occurs leadings to less hydrogen bonds between the analyte and the mag-MIPs' pores. Taking into consideration the obtained results the $\mathrm{pH} 3.0$ was used in the following experiments.

The most commonly used adsorption isotherms, Langmuir and Freundlich, were used to evaluate the capacity of adsorption of the pesticide on mag-MIPs and mag-NIPs. In general, it is believed that the Langmuir equation (Eq. (1)) better estimates a monolayer adsorption while the Freundlich equation (Eq. (2)) is more appropriate to noncovalent mag-MIPs adsorption, assuming an heterogeneous adsorption surface and active sites with different energy [45-48].

$\frac{C_{e}}{q_{e}}=\frac{1}{K_{L} q_{m}}+\frac{C_{e}}{q_{m}}$

$\ln q_{e}=\ln K_{F}+\frac{1}{n} \ln C_{e}$ where $C_{e}$ is the equilibrium concentration $\left(\mathrm{mg} \mathrm{L}^{-1}\right), \mathrm{q}_{\mathrm{e}}$ is the equilibrium adsorption capacity ( $\left.\mathrm{mg} \mathrm{g}^{-1}\right), \mathrm{q}_{\mathrm{m}}$ is the maximum adsorption capacity $\left(\mathrm{mg} \mathrm{g}^{-1}\right), \mathrm{K}_{\mathrm{L}}$ is the Langmuir affinity constant, $\left(\mathrm{L} \mathrm{g}^{-1}\right), \mathrm{K}_{\mathrm{F}}$ is the Freundlich adsorption constant $\left(\mathrm{mg} \mathrm{g}^{-1}\right)$ and $\mathrm{n}^{-1}$ is an empirical parameter related to the adsorption intensity which is affected by the heterogeneity of the material [46]. Both binding isotherms, at $25^{\circ} \mathrm{C}$, were plotted and are shown in Fig. 4 along with the obtained results. It seems clear that as the concentration of ametryn is increased the adsorption of ametryn on the mag-MIPs and mag-NIPs increases as well. The maximum adsorption capacity $\left(\mathrm{q}_{\mathrm{m}}\right)$ as well as the $\mathrm{K}_{\mathrm{L}}$ and $\mathrm{K}_{\mathrm{F}}$ were all greater in with mag-MIPs than the mag-NIPS. The non-linearity indicators $\left(\mathrm{n}^{-1}\right)$ for mag-MIPs and mag-NIPs were 0.13 and 0.29 , respectively, which suggests favorable adsorption on both materials while suggesting a greater non-linearity for mag-MIPs than to mag-NIPs. From the analysis of the $r^{2}$ values it is suggested that the Langmuir model better fits the adsorption equilibrium than the Freundlich model. All data suggest that the mag-MIPs' adsorption ability for ametryn was greater than of the mag-NIPs, this is quite likely due to MIPs' imprinted cavities, with high affinity binding sites, which were generated during cross-linking reactions.

Kinetics studies are also vital in adsorption phenomena and offer valuable information about the rate-controlling and binding mechanism [49]. The kinetic data was analyzed by adapted pseudo first order equation:

$\ln \left(q_{120}-q\right)=\ln q_{m}-k_{1} t$

where $\mathrm{t}$ is the time $(\mathrm{s}), \mathrm{q}_{120}$ is the adsorbed quantity at $120 \mathrm{~min}$ $\left(\mathrm{mg} \mathrm{g}^{-1}\right.$ ), when there was a plateau and the experiments were stopped, and $k_{1}$ is the rate constant $\left(\mathrm{s}^{-1}\right)$. The obtained values are shown in Table 2. The rate of adsorption of ametryn by mag-MIPs was higher than by mag-NIPs, furthermore mag-MIPs demonstrated higher binding capacity. Second order kinetic equations were also tested but not with the same well fitted results (data not shown). It is usually accepted in literature that pseudo-second order kinetics are adsorptions of chemical nature [50], for a pseudo-first order obtaining conclusions is a bit more difficult since we could be observing a physical adsorption, a one-step chemical adsorption or a several step chemical adsorption in which the first interaction is the rate-determining step.

\subsection{Analytical application}

The mag-MIPs were initial studied in terms of selectivity. As can be seen in Fig. 5, the competitive tests were conducted using various other analytes (atrazine, ciprofloxacin and folic acid). Selectivity $(\alpha)$ can be calculated using the following equation $[25,35,51]$ : 

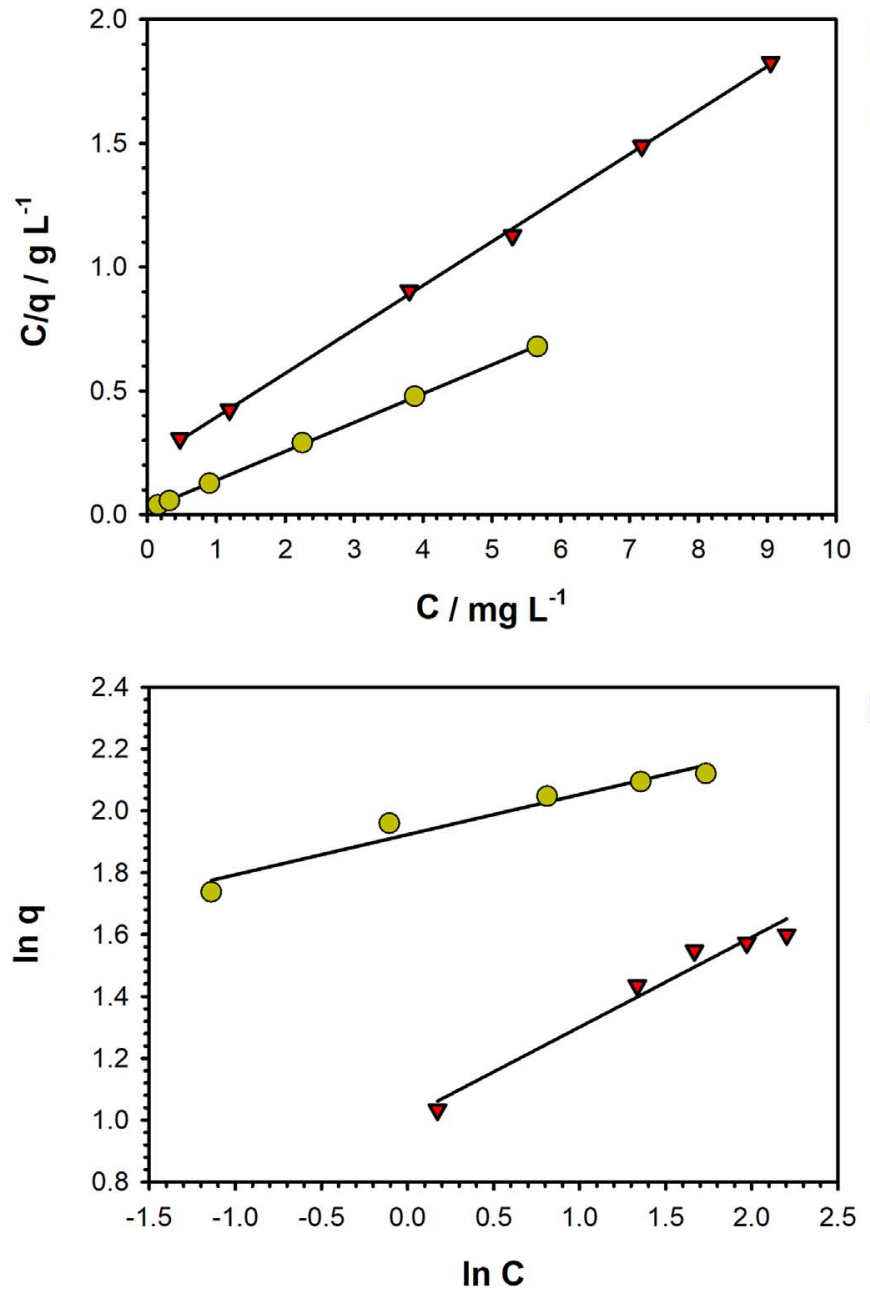

Table 2

The rate constant and binding capacity for the sorption of ametryn. Studies were performed at $25{ }^{\circ} \mathrm{C}$ with ametryn concentration of $10 \mathrm{mg} \mathrm{L}^{-1}$.

\begin{tabular}{llll}
\hline & $\mathrm{q}_{\mathrm{m}} / \mathrm{mg} \mathrm{g}^{-1}$ & $\mathrm{k}_{1} / \mathrm{s}^{-1}$ & $\mathrm{r}^{2}$ \\
\hline mag-MIPs & $8.16 \pm 0.96$ & $(25 \pm 4) \times 10^{-5}$ & 0.961 \\
mag-NIPs & $3.73 \pm 0.01$ & $(154 \pm 5) \times 10^{-6}$ & 0.990 \\
\hline
\end{tabular}

$\alpha=\frac{K_{d 1}}{K_{d 2}}$

where $\mathrm{K}_{\mathrm{d} 1}$ is the distribution coefficient of ametryn and $\mathrm{K}_{\mathrm{d} 2}$ is the distribution coefficient of the other compound used for comparison. $\mathrm{K}_{\mathrm{d}}$ $\left(\mathrm{mL} \mathrm{g}^{-1}\right)$ is calculated using the following formula [51]:

$K_{d}=\frac{q_{e}}{C_{e}}$

where $\mathrm{q}_{\mathrm{e}}$ is the experimental adsorption capacity ( $\mathrm{mg} \mathrm{g}^{-1}$ ), and $\mathrm{C}_{\mathrm{e}}$ is the equilibrium concentration ( $\mathrm{mg} \mathrm{g}^{-1}$ ), previously mentioned in the adsorption experiments. The $\alpha$ values were all above 4 , as expected, the lowest selectivity factor was obtained for atrazine, which is also a triazine herbicide. Still, considering the similarity between the two compounds it is a quite good $\alpha$ value. Also, as expected, the highest $\alpha$ value was obtained for folic acid which is a larger molecule and should not suitably fit into the mag-MIPs' pores.

The $\mathrm{K}_{\mathrm{d}}$ could also be used to calculate the imprinted factor (IF) using the following equation [35]:
Fig. 4. Equilibrium data and modeling for the adsorption of ametryn on mag-NIPs and mag-MIPs using the Langmuir model (on the left) and the Freundlich model (on the right). Langmuir and Freundlich isotherms constants and linear regression values. On the right, the values obtained from the fitting of the data. $r^{2}=0.9998$

$\mathrm{q}_{\mathrm{m}}=8.6 \pm 0.1 \mathrm{mg} \mathrm{g}^{-1}$

$\mathrm{K}_{\mathrm{L}}=5.2 \pm 0.6 \mathrm{~L} \mathrm{~g}^{-1}$

$\nabla$ Mag-NIPs

$r^{2}=0.9994$

$\mathrm{q}_{\mathrm{m}}=5.6 \pm 0.1 \mathrm{mg} \mathrm{g}^{-1}$

$\mathrm{K}_{\mathrm{L}}=0.8 \pm 0.1 \mathrm{~L} \mathrm{~g}^{-1}$

Freundlich

Mag-MIPS

$r^{2}=0.97$

$\mathrm{n}^{-1}=0.13 \pm 0.02$

$\mathrm{K}_{\mathrm{F}}=6.84 \pm 0.07 \mathrm{~g} \mathrm{mg}^{-1}$

\section{$\nabla$ Mag-NIPs}

$r^{2}=0.95$

$\mathrm{n}^{-1}=0.29 \pm 0.03$

$\mathrm{K}_{\mathrm{F}}=2.7 \pm 0.1 \mathrm{~g} \mathrm{mg}^{-1}$
$I F=\frac{K_{d \text { of mag-MIP }}}{K_{d \text { of mag-NIP }}}$

The IF should be above 1.0 and as high as possible. As can be seen in Fig. 5, the developed mag-MIPs indeed produced the best IF for ametryn (3.4), all other were below 2.

The calibration curve for ametryn had the following analytical parameters: $r^{2}$ of 0.9994 , Abs $(\mathrm{mV} \cdot \mathrm{min})=(129 \pm 2) \times 10^{7}$ [ametryn] $\left(\mathrm{mol} \mathrm{L}^{-1}\right)+(53 \pm 9)$, limit of detection (LOD) and quantification (LOQ) of 25 and $82 \mathrm{nmol} \mathrm{L}^{-1}$ (14 and $47 \mathrm{\mu g} \mathrm{kg}^{-1}$ in the samples), respectively (Fig. 6). LOD and LOQ were calculated as three and ten times the standard deviation of the intercept/slope, respectively. Recoveries results were of $102 \% \pm 6 \%$ in the studied food samples (studies were performed by spiking the samples). However, and thankfully, ametryn determination, performed by the standard addition method, was below the LOQ in the non-spiked food samples. The obtained analytical parameters are comparable to those find in literature for ametryne analysis. Zhao et al. combined MIPs with SPR achieving a LOD of $35 \mathrm{nmol} \mathrm{L}^{-1}$ [13], Sambe et al. [52] and Koohpaei et al. [42] used MIPs with HPLC-UV detection achieving a LOD of 0.1 and $44 \mathrm{nmol} \mathrm{L}^{-1}$, respectively. Djozan et al. [10] used MIPs as SPME with GC-MS detection achieved a LOD of $62 \mathrm{nmol} \mathrm{L}^{-1}$. These results corroborate the assumption that the synthetized mag-MIPs are a feasible tool for the extraction of ametryn in food samples aiming its analysis.

\section{Conclusions}

This work describes the successful development of selective magMIPs for the pesticide ametryn. Theoretical calculations were 


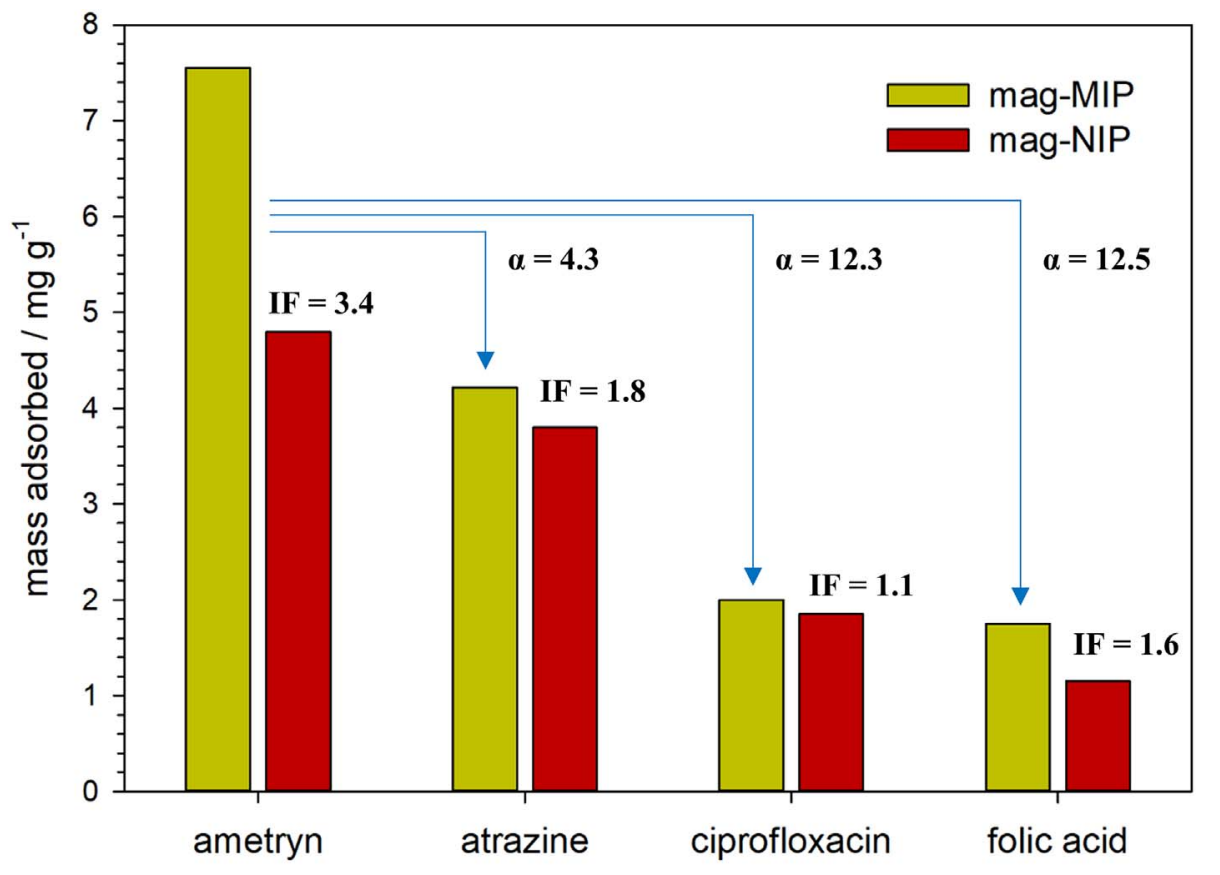

Fig. 5. Selectivity studies, using atrazine, ciprofloxacin and folic acid as the molecules of comparison.
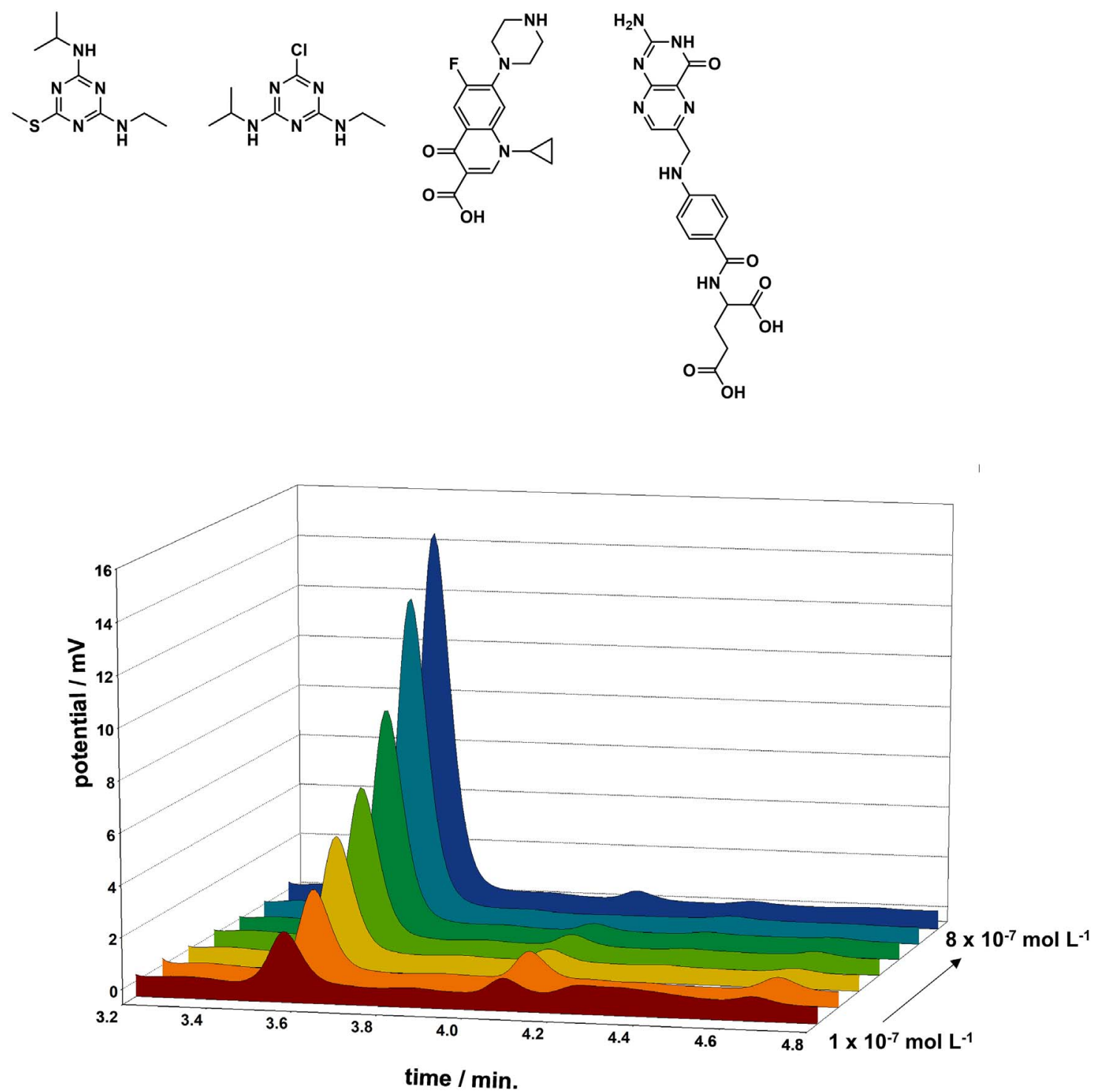

Fig. 6. Chromatograms of ametryn standards. 
performed for the pre-selection of the most suitable functional monomer able to interact with ametryn, the chosen compound was 2vinylpyridine. The synthesized mag-MIPs showed greater surface area and pore volume in comparison to the corresponding mag-NIPs, and IFs of 3.4. The mag-MIPs' adsorption behavior well-fitted a Langmuir model and pseudo first order kinetics. The developed methodology had a LOD and LOQ of 25 and $82 \mathrm{nmol} \mathrm{L}^{-1}$, respectively, recoveries ca. $100 \%$, and a $\mathrm{r}^{2}$ of 0.9994 .

\section{Acknowledgements}

The financial support of the National Council for Scientific and Technological Development (CNPq) Brazil, (151525/2013-7 and 400459/2012-4); FAPESP-Fundação de Amparo à Pesquisa do Estado de São Paulo (2014/25264-3 and 2016/06926-0) and Ministry of Economy and Competitiveness (MINECO), Madrid - Spain (BIO201341242-R) is appreciated. LMG (SFRH/BPD/76544/2011 and FCT/ 13277/4/8/2015/S) wishes to acknowledge Fundação para a Ciência e Tecnologia (FCT).

\section{Appendix A. Supplementary data}

Supplementary data to this article can be found online at https:// doi.org/10.1016/j.reactfunctpolym.2017.11.002.

\section{References}

[1] H. Sabik, R. Jeannot, B. Rondeau, Multiresidue methods using solid-phase extrac tion techniques for monitoring priority pesticides, including triazines and degradation products, in ground and surface waters, J. Chromatogr. A 885 (2000) 217-236, http://dx.doi.org/10.1016/S0021-9673(99)01084-5.

[2] A.E. Jacomini, P.B. de Camargo, W.E.P. Avelar, P.S. Bonato, Assessment of Ametryn contamination in river water, river sediment, and mollusk bivalves in São Paulo State, Brazil, Arch. Environ. Contam. Toxicol. 60 (2011) 452-461, http://dx.doi. org/10.1007/s00244-010-9552-z.

[3] A.E. Jacomini, P.B. de Camargo, W.E.P. Avelar, P.S. Bonato, Determination of ametryn in river water, river sediment and bivalve mussels by liquid chromatography-tandem mass spectrometry, J. Braz. Chem. Soc. 20 (2009) 107-116, http:// dx.doi.org/10.1590/S0103-50532009000100018.

[4] M. Garmouma, M. Blanchard, A. Chesterikoff, P. Ansart, M. Chevreuil, Seasonal transport of herbicides (triazines and phenylureas) in a small stream draining an agricultural basin: Mélarchez (France), Water Res. 31 (1997) 1489-1503, http://dx. doi.org/10.1016/S0043-1354(96)00400-9.

[5] A.L. dos Santos, E.A. Batista, L.M. Gonçalves, M. del Pilar, T. Sotomayor, Modified carbon paste electrode for the electrochemical sensing of 3,5,6-trichloro-2-pyridinol, Int. J. Environ. Anal. Chem. 97 (2017) 159-167, http://dx.doi.org/10.1080/ 03067319.2017.1291809.

[6] V. Yusa, M. Millet, C. Coscolla, M. Roca, Analytical methods for human biomonitoring of pesticides. A review, Anal. Chim. Acta 891 (2015) 15-31, http://dx.doi. org/10.1016/j.aca.2015.05.032.

[7] S. Liu, Z. Zheng, X. Li, Advances in pesticide biosensors: current status, challenges, and future perspectives, Anal. Bioanal. Chem. 405 (2013) 63-90, http://dx.doi.org/ 10.1007/s00216-012-6299-6.

[8] H. Sabik, R. Jeannot, Determination of organonitrogen pesticides in large volumes of surface water by liquid-liquid and solid-phase extraction using gas chromatography with nitrogen-phosphorus detection and liquid chromatography with atmospheric pressure chemical ionization ma, J. Chromatogr. A 818 (1998) 197-207, http://dx.doi.org/10.1016/S0021-9673(98)00555-X.

[9] C. Aguilar, S. Peñalver, E. Pocurull, F. Borrull, R. Marcé, Solid-phase microextraction and gas chromatography with mass spectrometric detection for the determination of pesticides in aqueous samples, J. Chromatogr. A 795 (1998) 105-115, http://dx.doi.org/10.1016/S0021-9673(97)00917-5.

[10] D. Djozan, M. Mahkam, B. Ebrahimi, Preparation and binding study of solid-phase microextraction fiber on the basis of ametryn-imprinted polymer, J. Chromatogr. A 1216 (2009) 2211-2219, http://dx.doi.org/10.1016/j.chroma.2008.12.101.

[11] O. Tavares, S. Morais, P. Paíga, C. Delerue-Matos, Determination of ametryn in soils via microwave-assisted solvent extraction coupled to anodic stripping voltammetry with a gold ultramicroelectrode, Anal. Bioanal. Chem. 382 (2005) 477-484, http:// dx.doi.org/10.1007/s00216-004-3045-8.

[12] Y. Chen, Z.-P. Chen, J.-W. Jin, R.-Q. Yu, Quantitative determination of ametryn in river water using surface-enhanced Raman spectroscopy coupled with an advanced chemometric model, Chemom. Intell. Lab. Syst. 142 (2015) 166-171, http://dx.doi. org/10.1016/j.chemolab.2015.01.012.

[13] N. Zhao, C. Chen, J. Zhou, Surface plasmon resonance detection of ametryn using a molecularly imprinted sensing film prepared by surface-initiated atom transfer radical polymerization, Sensors Actuators B Chem. 166-167 (2012) 473-479, http:// dx.doi.org/10.1016/j.snb.2012.02.089.
[14] A. Mohammadi, A. Ameli, N. Alizadeh, Headspace solid-phase microextraction using a dodecylsulfate-doped polypyrrole film coupled to ion mobility spectrometry for the simultaneous determination of atrazine and ametryn in soil and water samples, Talanta 78 (2009) 1107-1114, http://dx.doi.org/10.1016/j.talanta.2009. 01.025 .

[15] R. Fang, G. Chen, L. Yi, Y. Shao, L. Zhang, Q. Cai, J. Xiao, Determination of eight triazine herbicide residues in cereal and vegetable by micellar electrokinetic capillary chromatography with on-line sweeping, Food Chem. 145 (2014) 41-48, http://dx.doi.org/10.1016/j.foodchem.2013.08.028.

[16] L.M. Gonçalves, I.M. Valente, J.A. Rodrigues, Recent advances in membrane-aided extraction and separation for analytical purposes, Sep. Purif. Rev. 46 (2017) 179-194, http://dx.doi.org/10.1080/15422119.2016.1235050.

[17] Y. Liu, L.Y. Ma, Y.C. Lu, S.S. Jiang, H.J. Wu, H. Yang, Comprehensive analysis of degradation and accumulation of ametryn in soils and in wheat, maize, ryegrass and alfalfa plants, Ecotoxicol. Environ. Saf. 140 (2017) 264-270, http://dx.doi.org/10. 1016/j.ecoenv. 2017.02.053.

[18] V. Pichon, F. Chapuis-Hugon, Role of molecularly imprinted polymers for selective determination of environmental pollutants-a review, Anal. Chim. Acta 622 (2008) 48-61, http://dx.doi.org/10.1016/j.aca.2008.05.057.

[19] F. Omidi, M. Behbahani, S. Samadi, A. Sedighi, S.J. Shahtaheri, Coupling of molecular imprinted polymer nanoparticles by high performance liquid chromatography as an efficient technique for sensitive and selective trace determination of 4chloro-2-methylphenoxy acetic acid in complex matrices, Iran. J. Public Health 43 (2014) 645-657 http://www.ncbi.nlm.nih.gov/pmc/articles/PMC4449413/.

[20] F. Omidi, M. Behbahani, H. Sadeghi Abandansari, A. Sedighi, S.J. Shahtaheri, Application of molecular imprinted polymer nanoparticles as a selective solid phase extraction for preconcentration and trace determination of 2,4-dichlorophenoxyacetic acid in the human urine and different water samples, J. Environ. Health Sci. Eng. 12 (2014) 137, , http://dx.doi.org/10.1186/s40201-014 0137-z.

[21] M. Khadem, F. Faridbod, P. Norouzi, A. Rahimi Foroushani, M.R. Ganjali, S.J. Shahtaheri, R. Yarahmadi, Modification of carbon paste electrode based on molecularly imprinted polymer for electrochemical determination of diazinon in biological and environmental samples, Electroanalysis 29 (2017) 708-715, http:// dx.doi.org/10.1002/elan.201600293.

[22] M. Khadem, F. Faridbod, P. Norouzi, A.R. Foroushani, M.R. Ganjali, S.J. Shahtaheri, Biomimetic electrochemical sensor based on molecularly imprinted polymer for dicloran pesticide determination in biological and environmental samples, J. Iran. Chem. Soc. 13 (2016) 2077-2084, http://dx.doi.org/10.1007/s13738-016-0925-8.

[23] B. Ara, Z. Chen, J. Shah, M. Rasul Jan, L. Ye, Preparation and characterization of uniform molecularly imprinted polymer beads for separation of triazine herbicides, J. Appl. Polym. Sci. 126 (2012) 315-321, http://dx.doi.org/10.1002/app.36882.

[24] L. Chen, B. Li, Application of magnetic molecularly imprinted polymers in analytical chemistry, Anal. Methods 4 (2012) 2613, http://dx.doi.org/10.1039/ c2ay25354b.

[25] R.J. Uzuriaga-Sánchez, A. Wong, S. Khan, M.I. Pividori, G. Picasso, M.D.P.T. Sotomayor, Synthesis of a new magnetic-MIP for the selective detection of 1-chloro-2,4-dinitrobenzene, a highly allergenic compound, Mater. Sci. Eng. C (2016), http://dx.doi.org/10.1016/j.msec.2016.12.019.

[26] R.J. Uzuriaga-Sánchez, S. Khan, A. Wong, G. Picasso, M.I. Pividori, M.D.P.T. Sotomayor, Magnetically separable polymer (Mag-MIP) for selective analysis of biotin in food samples, Food Chem. 190 (2016) 460-467, http://dx.doi. org/10.1016/j.foodchem.2015.05.129.

[27] S. Hussain, S. Khan, S. Gul, M.I. Pividori, M.D.P.T. Sotomayor, A novel core@shell magnetic molecular imprinted nanoparticles for selective determination of folic acid in different food samples, React. Funct. Polym. 106 (2016) 51-56, http://dx. doi.org/10.1016/j.reactfunctpolym.2016.07.011.

[28] A. Ben Aissa, A. Herrera-Chacon, R.R. Pupin, M.D.P.T. Sotomayor, M.I. Pividori, Magnetic molecularly imprinted polymer for the isolation and detection of biotin and biotinylated biomolecules, Biosens. Bioelectron. 88 (2017) 101-108, http://dx. doi.org/10.1016/j.bios.2016.07.096.

[29] M.M. Pedroso, M.V. Foguel, D.H.S. Silva, M. del P.T. Sotomayor, H. Yamanaka, Electrochemical sensor for dodecyl gallate determination based on electropolymerized molecularly imprinted polymer, Sensors Actuators B Chem. 253 (2017) 180-186, http://dx.doi.org/10.1016/j.snb.2017.06.127.

[30] S. Ansari, Application of magnetic molecularly imprinted polymer as a versatile and highly selective tool in food and environmental analysis: recent developments and trends, TrAC Trends Anal. Chem. 90 (2017) 89-106, http://dx.doi.org/10.1016/j. trac.2017.03.001.

[31] P. Yáñez-Sedeño, S. Campuzano, J.M. Pingarrón, Electrochemical sensors based on magnetic molecularly imprinted polymers: a review, Anal. Chim. Acta 960 (2017) 1-17, http://dx.doi.org/10.1016/j.aca.2017.01.003.

[32] S. Ansari, M. Karimi, Recent configurations and progressive uses of magnetic molecularly imprinted polymers for drug analysis, Talanta 167 (2017) 470-485, http://dx.doi.org/10.1016/j.talanta.2017.02.049.

[33] L.D. Marestoni, A. Wong, G.T. Feliciano, M.R.R. Marchi, C.R.T. Tarley, M.D.P.T. Sotomayor, Semi-empirical quantum chemistry method for pre-polymerization rational design of ciprofloxacin imprinted polymer and adsorption studies, J. Braz. Chem. Soc. 27 (2015) 109-118, http://dx.doi.org/10.5935/01035053.20150256.

[34] F. Lu, M. Sun, L. Fan, H. Qiu, X. Li, C. Luo, Flow injection chemiluminescence sensor based on core-shell magnetic molecularly imprinted nanoparticles for determination of chrysoidine in food samples, Sensors Actuators B Chem. 173 (2012) 591-598, http://dx.doi.org/10.1016/j.snb.2012.07.069.

[35] C.R.T. Tarley, M.D.P.T. Sotomayor, L.T. Kubota, Polímeros biomiméticos em química analítica. Parte 1: preparo e aplicações de MIP ("Molecularly Imprinted 
Polymers") em técnicas de extração e separação, Quim Nova 28 (2005) 1076-1086, http://dx.doi.org/10.1590/S0100-40422005000600024.

[36] K. Farrington, F. Regan, Investigation of the nature of MIP recognition: the development and characterisation of a MIP for Ibuprofen, Biosens. Bioelectron. 22 (2007) 1138-1146, http://dx.doi.org/10.1016/j.bios.2006.06.025.

[37] L.M. Madikizela, N.T. Tavengwa, L. Chimuka, Applications of molecularly imprinted polymers for solid-phase extraction of non-steroidal anti-inflammatory drugs and analgesics from environmental waters and biological samples, J. Pharm. Biomed. Anal. (2017), http://dx.doi.org/10.1016/j.jpba.2017.04.010.

[38] L.M. Madikizela, P.S. Mdluli, L. Chimuka, Experimental and theoretical study of molecular interactions between 2-vinyl pyridine and acidic pharmaceuticals used as multi-template molecules in molecularly imprinted polymer, React. Funct. Polym. 103 (2016) 33-43, http://dx.doi.org/10.1016/j.reactfunctpolym.2016.03.017.

[39] N.N. Mohamad Yusof, E. Tanioka, T. Kobayashi, Molecularly imprinted polymer particles having coordinated hydrogen bonding in covalent-imprinting for efficient recognition towards vanillin, Sep. Purif. Technol. 122 (2014) 341-349, http://dx. doi.org/10.1016/j.seppur.2013.11.028.

[40] M.R. Gama, C.B.G. Bottoli, Molecularly imprinted polymers for bioanalytical sample preparation, J. Chromatogr. B 1043 (2017) 107-121, http://dx.doi.org/10. 1016/j.jchromb.2016.09.045.

[41] A.R. Koohpaei, S.J. Shahtaheri, M.R. Ganjali, A.R. Forushani, F. Golbabaei, Application of multivariate analysis to the screening of molecularly imprinted polymers (MIPs) for ametryn, Talanta 75 (2008) 978-986, http://dx.doi.org/10, 1016/j.talanta.2007.12.046.

[42] A.R. Koohpaei, S.J. Shahtaheri, M.R. Ganjali, A.R. Forushani, F. Golbabaei, Optimization of solid-phase extraction using developed modern sorbent for trace determination of ametryn in environmental matrices, J. Hazard. Mater. 170 (2009) 1247-1255, http://dx.doi.org/10.1016/j.jhazmat.2009.05.125.

[43] A. Wong, M.V. Foguel, S. Khan, F.M. De Oliveira, C.R.T. Tarley, M.D.P.T. Sotomayor, Development of an electrochemical sensor modified with MWCNT-COOH and MIP for detection of Diuron, Electrochim. Acta 182 (2015) 122-130, http://dx.doi.org/10.1016/j.electacta.2015.09.054.

[44] L.O.C. Silva, A.A. Silva, L. D'Antonino, M.E.L.R. Queiroz, C.F. Lima, F.C.L. Freitas,
Sorção e dessorção do ametryn em Latossolos brasileiros, Planta Daninha. 30 (2012) 633-640, http://dx.doi.org/10.1590/S0100-83582012000300020.

[45] Y.-L. Zhang, J. Zhang, C.-M. Dai, X.-F. Zhou, S.-G. Liu, Sorption of carbamazepine from water by magnetic molecularly imprinted polymers based on chitosan- $\mathrm{Fe}_{3} \mathrm{O}_{4}$, Carbohydr. Polym. 97 (2013) 809-816, http://dx.doi.org/10.1016/j.carbpol.2013. 05.072 .

[46] Y. Liu, X. Meng, M. Luo, M. Meng, L. Ni, J. Qiu, Z. Hu, F. Liu, G. Zhong, Z. Liu, Y. Yan, Synthesis of hydrophilic surface ion-imprinted polymer based on graphene oxide for removal of strontium from aqueous solution, J. Mater. Chem. A 3 (2015) 1287-1297, http://dx.doi.org/10.1039/C4TA04908J.

[47] P.J. Magalhães, J.S. Vieira, L.M. Gonçalves, J.G. Pacheco, L.F. Guido, A.A. Barros, Isolation of phenolic compounds from hop extracts using polyvinylpolypyrrolidone: characterization by high-performance liquid chromatography-diode array detection-electrospray tandem mass spectrometry, J. Chromatogr. A 1217 (2010) 3258-3268, http://dx.doi.org/10.1016/j.chroma.2009.10.068.

[48] S. Khan, M. Ishaq, I. Ahmad, S. Hussain, H. Ullah, Evaluation of coal as adsorbent for phosphate removal, Arab. J. Geosci. 6 (2013) 1113-1117, http://dx.doi.org/10. 1007/s12517-011-0431-3.

[49] S. Hussain, S. Gul, S. Khan, H. ur Rehman, Retention studies of chromium (VI) from aqueous solution on the surface of a novel carbonaceous material, Arab. J. Geosci. 6 (2013) 4547-4556, http://dx.doi.org/10.1007/s12517-012-0745-9.

[50] L.M. Madikizela, L. Chimuka, Synthesis, adsorption and selectivity studies of a polymer imprinted with naproxen, ibuprofen and diclofenac, J. Environ. Chem. Eng. 4 ( (2016) 4029-4037, http://dx.doi.org/10.1016/j.jece.2016.09.012.

[51] X.-Y. Gong, X.-J. Cao, Preparation of molecularly imprinted polymers for artemisinin based on the surfaces of silica gel, J. Biotechnol. 153 (2011) 8-14, http://dx doi.org/10.1016/j.jbiotec.2011.02.005.

[52] H. Sambe, K. Hoshina, J. Haginaka, Molecularly imprinted polymers for triazine herbicides prepared by multi-step swelling and polymerization method: their application to the determination of methylthiotriazine herbicides in river water, J. Chromatogr. A. 1152 (2007) 130-137, http://dx.doi.org/10.1016/j.chroma.2006. 09.003 . 